\title{
Proveniência de arenitos albianos (Grupo Itapecuru), borda leste da bacia de São Luís-Grajaú, Maranhão, usando análise de minerais pesados e química mineral \\ Provenance of Albian sandstones (Itapecuru Group), eastern border of São Luís-Grajaú Basin, Maranhão, using heavy mineral analysis and mineral chemistry
}

\author{
Anderson Conceição Mendes ${ }^{1}$ \\ Werner Truckenbrodt"
}

Resumo: Depósitos albianos da bacia de São Luís-Grajaú, antigamente conhecidos apenas em subsuperfície como 'Unidade Indiferenciada' do Grupo Itapecuru, foram recentemente encontrados ao longo do rio Itapecuru, na parte leste desta bacia. São argilitos avermelhados, esverdeados a cinzas, arenitos estratificados e maciços e subordinadamente calcários, interpretados como depósitos de delta progradante para ENE/E e ESE e conectado a uma plataforma restrita. Para determinar a proveniência de arenitos albianos, foram coletadas 18 amostras para estudos de minerais pesados (fração 0,062-0,125 mm) usando-se microscópio petrográfico convencional e microscópio eletrônico de varredura. Os arenitos foram classificados como quartzo-arenito moderadamente a bem selecionado, cimentado por dolomita, cujos principais minerais pesados são zircão (4-70\%), granada (12-74\%), turmalina (3-20\%), estaurolita (1-9\%), rutilo (1-8\%) e barita (0-55\%), enquanto cianita, anatásio (autigênico), anfibólio (hornblenda), andaluzita, sillimanita, espinélio e ilmenita ocorrem raramente. A maioria dos grãos é irregular angulosa, mas grãos bem arredondados, particularmente de turmalina e zircão, também estão presentes. Texturas superficiais incluem fraturas conchoidais, marcas de percussão em $\vee$ e pequenos buracos, estes últimos em grãos arredondados de turmalina e zircão, enquanto feições de corrosão estão principalmente presentes em barita (cavidades rômbicas), cianita, estaurolita (superfície mamilar) e granada (facetas bem formadas por dissolução). Grãos de zircão, com texturas de zoneamento oscilatório e razões $U / T h \geq 0,5$ e Zr/Hf média de 29, indicam proveniência de granitos e migmatitos, enquanto os tipos de turmalina, determinados como dravita e shorlita, são oriundos, principalmente, de metapelitos e metapsamitos aluminosos e/ou pobres em Al, com menor contribuição de granitos e rochas meta-ultramáficas. As granadas, por sua vez, são ricas em almandina e têm baixos teores dos componentes de espessartita, grossulária e piropo. Suas fontes potenciais são rochas metamórficas de baixo a médio grau e granitos. Com base em análises de minerais pesados e progradação do sistema deltaico para ENE/E e ESE, as áreas mais prováveis como fontes potenciais de arenitos albianos são o cráton São Luís, os cinturões neoproterozóicos Araguaia e Gurupi, bem como a bacia paleozóica do Parnaíba, esta fornecendo sedimentos de grãos arredondados.

Palavras-chave: Proveniência. Minerais pesados. Arenitos albianos. Bacia de São Luís-Grajaú.

\footnotetext{
Universidade Federal do Pará. Instituto de Geociências. Belém, Pará, Brasil (aacmendes@yahoo.com.br).

"Iniversidade Federal do Pará. Instituto de Geociências. Belém, Pará, Brasil (trucken@ufpa.br).
}

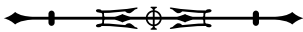


Abstract: Albian deposits from the São Luis-Grajaú Basin, formerly recognized only in the subsurface, have been recently found along the Itapecuru river, eastern part of this basin. These deposits consist of red, gray to greenish mudstones, cross-bedded and massive sandstone and subordinately limestones, interpreted as deposits of a to ENE/E and ESE prograding delta connected to a restricted platform. In order to understand the provenance of Albian sandstones, 18 samples were collected for heavy mineral analysis (fraction 0,062-0,125 mm) using a conventional petrographic microscope and scanning electron microscope. The sandstones have been classified as moderately to well sorted, dolomite-cemented quartz-arenites whose heavy-mineral suite consists of zircon (4-70\%), garnet (12-74\%), tourmaline (3-20\%), staurolite (1-9\%), rutile (1-8\%) and baryte (0-55\%), while kyanite, anatase (authigenic), calcic-amphibole, andalusite, sillimanite, spinel and ilmenite occur more rarely. The majority of the grains is angular irregular, but well rounded grains, particularly tourmaline and zircon, are also present. Surface textures include conchoidal fractures, percussion marks in $\mathrm{V}$ and diminute pits, the latter in rounded tourmaline and zircon grains, while corrosion features are mainly present in baryte (rhombic cavities), kyanite, staurolite (surface mammillae) and garnet (well-formed etch-facets). Zircon grains, with oscillatory zoning textures, $\mathrm{U} / \mathrm{Th}$ ratio $\geq 0,5$ and mean $\mathrm{Zr} / \mathrm{Hf}$ ratio of 29, are mainly derived from granites and probably migmatites. Plots on $\mathrm{Zr} / \mathrm{Hf}-\mathrm{Y}$ and $\mathrm{Hf}-\mathrm{Y}$-Nb diagrams show that this mineral can be related to at least two different sources. The tourmaline types, determined as dravite and schorl, indicate provenance mainly from aluminous and/or Al-poor metapelites and metapsammites with smaller contribution from granitic and meta-ultramafic rocks. Garnet is rich in almandine and has relatively low spessartine, grossular and pyrope contents whose potential source rocks are low- to medium-grade metamorphic rocks and granites. Based on their heavy-mineral suite and the progradation of the delta system to ENE/E and ESE, the most likely source areas of the studied Albian sandstones are the São Luís Craton, the Neoproterozoic Araguaia and Gurupi belts as well as the Paleozoic Parnaíba Basin, the latter supplying sediments of rounded grains.

Keywords: Provenance. Heavy minerals. Albian sandstones. São Luís-Grajaú Basin. 


\section{INTRODUÇÃO}

Minerais pesados têm sido utilizados há muito tempo em pesquisa de proveniência de arenitos. Mas a identificação de rochas-fonte é, muitas vezes, problemática, já que transporte, intemperismo e diagênese são fatores que causam fracionamento destes minerais em função da sua forma, densidade, resistência física e estabilidade química, levando à perda parcial de informações de proveniência (Morton, 1985a; Morton \& Hallsworth, 1994, 1999). Contudo, análises químicas de grãos individuais de minerais pesados detríticos podem minimizar este efeito e estabelecer uma relação direta com as características da rocha-fonte (Morton, 1985b, 1991). Turmalina, zircão e granada, minerais com grande resistência física e estabilidade química aos processos geológicos superficiais, têm sido muito utilizados para este tipo de análise (Henry \& Guidotti, 1985; Owen, 1987; Morton, 1991; Anani, 1999). Além disso, grau de arredondamento e texturas superficiais de minerais pesados informam sobre transporte, intemperismo e diagênese.

Este trabalho tem como objetivo caracterizar arenitos deltaicos, de idade albiana (Grupo Itapecuru), e sua assembléia de minerais pesados na borda leste da bacia de São LuísGrajaú (Figura 1A) e, com base nestes dados e informações paleoambientais, especialmente de paleocorrentes, inferir sobre sua possível proveniência. Além disso, tentou-se entender se existe uma relação entre os minerais pesados e as associações de fácies do complexo deltaico. Os arenitos albianos, antigamente conhecidos apenas em subsuperficie e posicionados na 'Unidade Indiferenciada' do Grupo Itapecuru (Rossetti \& Truckenbrodt, 1997), foram depositados em um sistema deltaico progradante para ENE/E e ESE, conectado com uma plataforma restrita (Miranda \& Rossetti, 2006). As amostras para este estudo foram coletadas em 13 exposições ao longo do rio Itapecuru, entre as localidades de Coroatá e Cigana (Figura 1).

\section{GEOLOGIA DA BACIA DE SÃO LUÍS-GRAJAÚ}

A bacia de São Luís-Grajaú, na região centro-norte do Brasil, consiste, principalmente, em depósitos cretáceos que encobrem extensa área do Maranhão e noroeste do Pará. A história destes depósitos está vinculada ao evento de abertura do oceano Atlântico, que originou diversas bacias nesta região (Barreirinhas e BragançaVizeu), inseridas, como a de São Luís-Grajaú, no Sistema de Graben Gurupi, um rifte intracontinental abandonado (Tese de Doutorado de R. P. Azevedo, de 1991, intitulada "Tectonic evolution of Brazilian Equatorial continental margin basins”; Góes \& Rossetti, 2001). O embasamento da bacia de São Luís-Grajaú é representado por rochas pré-cambrianas do cráton amazônico, dos cinturões Araguaia-Tocantins e Gurupi, e de rochas paleozóicas da bacia do Parnaíba (Figura 1A).

As rochas cretáceas da bacia de São Luís-Grajaú são interpretadas na forma de três sequências deposicionais de segunda ordem (S1, S2 e S3; Rossetti, 2001), limitadas por discordâncias regionais (Figura 2). Vários estudos abordaram os aspectos faciológicos e estratigráficos destas unidades (Rossetti et al., 2001a; Paz \& Rossetti, 2001; Lima \& Rossetti, 2001; Anaisse Jr. et al., 2001; Santos Júnior \& Rossetti, 2003). A sequência S1 (neoaptiana/eoalbiana) inclui as formações Codó e Grajaú, que consistem em arenitos, folhelhos, calcários e evaporitos, de ambientes marinho raso, lacustre e fluvio-deltaico. A sequência S2 (eo/mesoalbiana) compreende a parte inferior da 'Unidade Indiferenciada' (Rossetti \& Truckenbrodt, 1997), composta de arenitos e argilitos acumulados em ambientes marinho raso e fluvio/deltaico. Já a sequência S3 (mesoalbiana/neocretácea) inclui a porção superior da 'Unidade Indiferenciada' e as formações Alcântara (albiana/ cenomaniana) e Cujupe (neocretácea), constituídas por argilitos e arenitos de ambientes estuarinos de vales incisos (Rossetti, 2001). As sequências 2 e 3 estão inseridas no Grupo Itapecuru (Figura 2).

Depósitos albianos do Grupo Itapecuru, na área de trabalho, foram primeiramente descritos por Rossetti et al. (2001a), constituídos, principalmente, de pelitos e arenitos. Em estudos ao longo do rio Itapecuru, Miranda \& Rossetti (2006) reconheceram 12 fácies, que agruparam em cinco associações atribuídas a ambientes de (a) planície deltaica, 
(b) frente deltaica, (c) frente deltaica com retrabalhamento de ondas, (d) barra distal e (e) prodelta/plataforma restrita/ planície de lama (Figura 1B). Segundo estes autores, os depósitos de planície deltaica são constituídos por argilitos negros, ricos em restos vegetais, e arenitos finos, enquanto os depósitos de frente deltaica são caracterizados por arenitos finos, que ocorrem sob forma de lobos amalgamados ou separados por finas camadas de argilito e/ou conglomerados intraformacionais. Depósitos de frente deltaica com retrabalhamento por ondas consistem em arenitos finos apresentando estratificação cruzada de baixo ângulo, laminação ondulante e estruturas de corte e preenchimento. Os depósitos de barra distal são constituídos por depósitos argilosos e heterolíticos, intercalados com camadas de arenito, localmente calcífero, cuja geometria varia de lobada a tabular. $\bigcirc$ conjunto

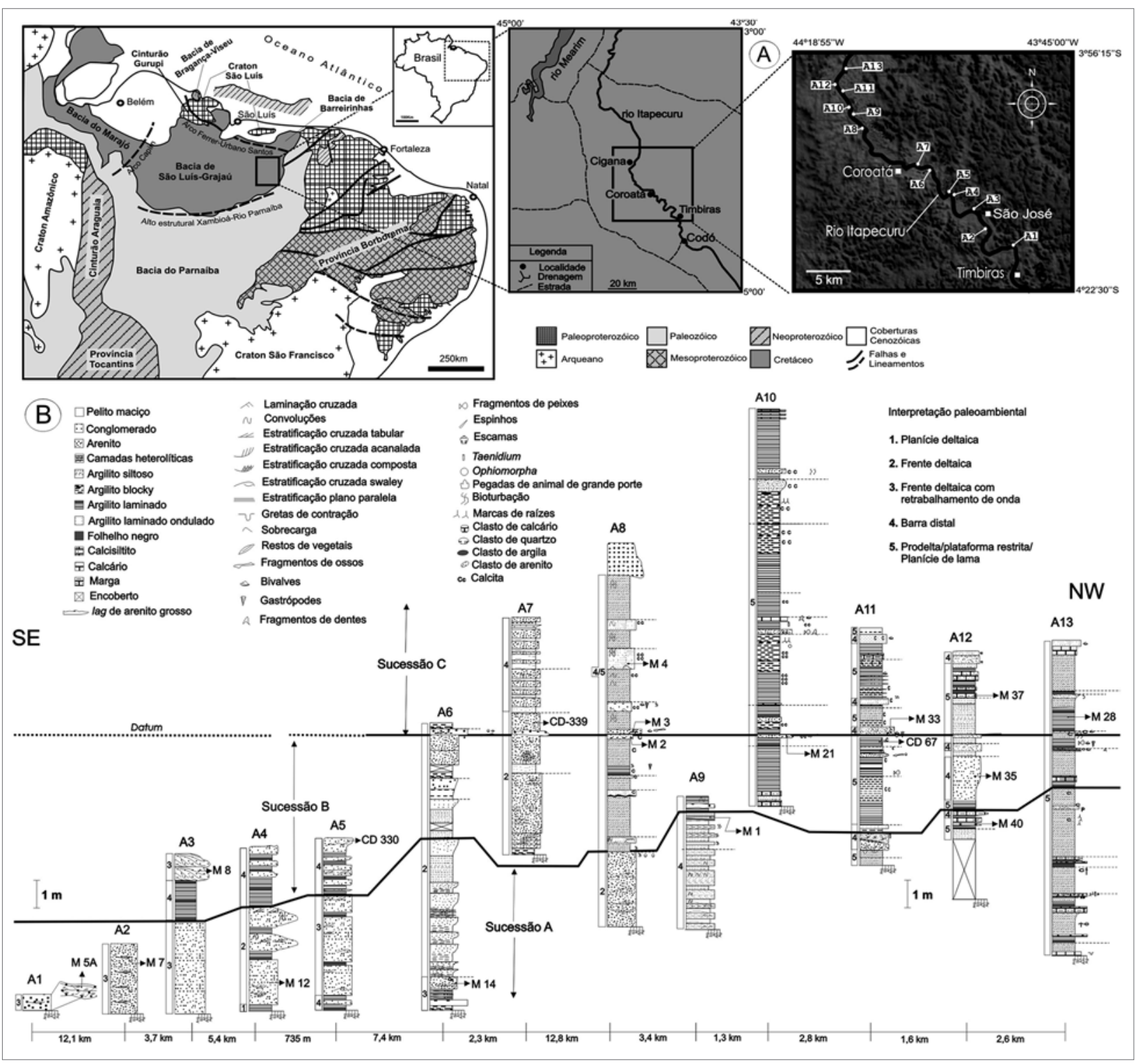

Figura 1. A) Mapa de localização e B) Perfis litoestratigráficos com posição de origem das amostras analisadas.

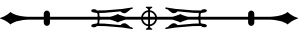


litológico mais fino é representado pela fácie prodelta/ plataforma restrita/planície de lama, incluindo argilitos e calcários com grãos terrígenos.

\section{GEOLOGIA DO EMBASAMENTO}

Seis unidades tectônicas do embasamento podem ser diferenciadas cercando e/ou sotopondo a bacia de São Luís-Grajaú, na área de estudo, incluindo os crátons amazônico e São Luís com suas faixas neoproterozóicas (Araguaia, Gurupi) associadas, localizados a oeste e noroeste da bacia, respectivamente; a Província de

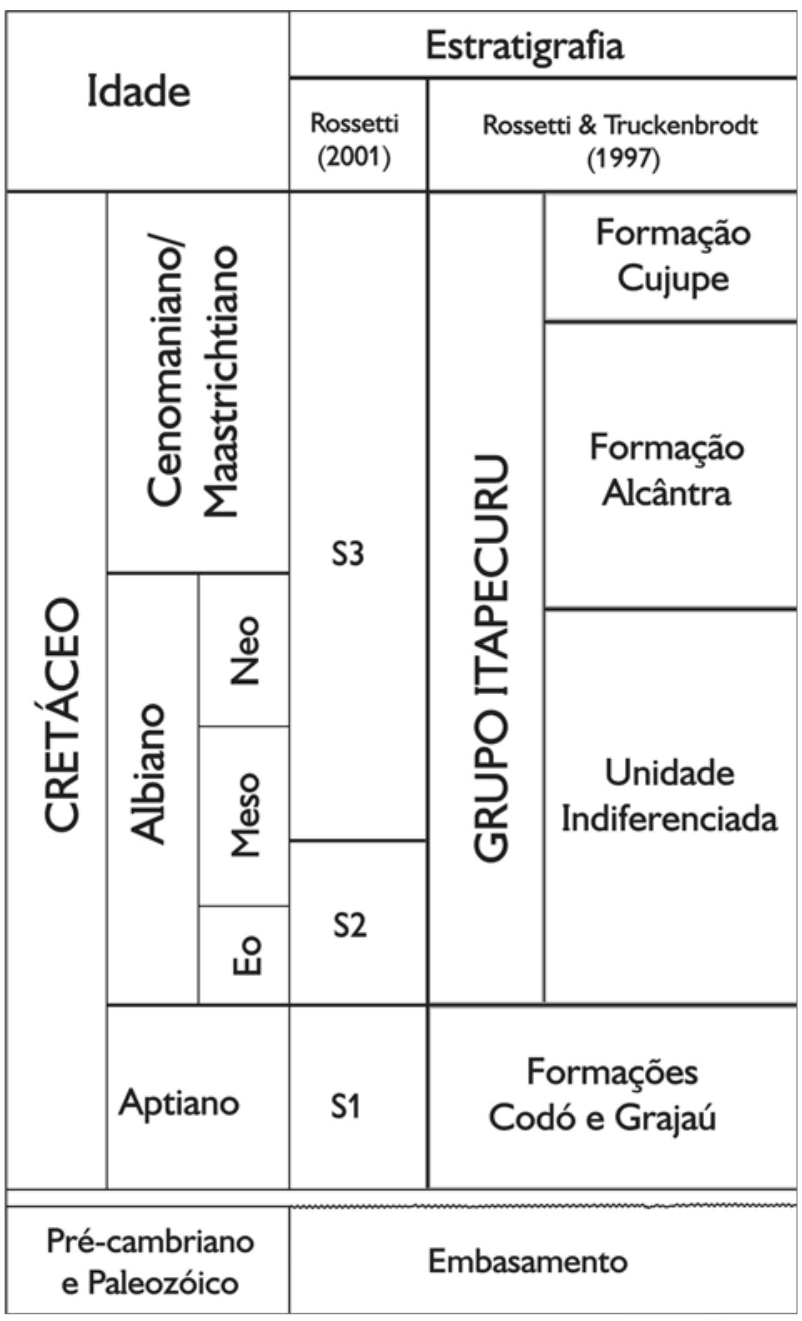

Figura 2. Carta estratigráfica dos depósitos cretáceos da bacia de São Luís-Grajaú (modificado de Rossetti, 2001).
Borborema, a nordeste; bem como a bacia paleozóica de Parnaíba, a leste e sul (Figura 1B).

O cráton amazônico é composto por gnaisses, migmatitos, granodioritos, riolitos, andesitos, sienitos, monzonitos, rochas metassedimentares, bem como rochas metabásicas e ultrabásicas, granulitos, anfibolitos e granitóides (Cordani et al., 1984). No seu limite oriental, ocorre a faixa Araguaia, constituída, principalmente, de quartzitos, metaconglomerados, xistos, metagrauvacas, metarcósios e anfibolitos (Hasui et al., 1984a). Esta unidade, na porção leste, está recoberta por depósitos paleozóicos da bacia do Parnaíba. A faixa Gurupi, que ocorre a noroeste da bacia de São Luís-Grajaú, é composta de rochas tonalíticas, metavulcânicas, granitos, quartzitos, xistos, ardósias e gnaisses (Hasui et al., 1984b; Moura et al., 2003). Contorna a porção sudoeste do cráton São Luís, que consiste em rochas granitóides, metavulcânicas e metassedimentares (Hasui et al., 1984b; Moura et al., 2003; Klein et al., 2005). A Província Borborema, por sua vez, contém gnaisses, migmatitos, granitos, rochas metassedimentares e metavulcânicas (Santos \& Brito Neves, 1984; Brito Neves et al., 2001).

A bacia do Parnaíba, com área de aproximadamente $600.000 \mathrm{~km}^{2}$, constitui o principal embasamento dos depósitos estudados. Esta bacia é representada por três ciclos deposicionais (conforme a Dissertação de Mestrado de F. M. B. Cunha, defendida em 1986, intitulada "Evolução Paleozóica da Sinéclise do Parnaíba e seu Arcabouço Tectônico"). O primeiro refere-se ao Grupo Serra Grande (Ordoviciano-Devoniano inferior), composto pelas formações Ipu, Tianguá e Jaicós, e representa uma sequência flúvio-glacial, seguida de transgressão marinha e regressão bem marcada no topo (Caputo \& Lima, 1984; Góes et al., 1992). O segundo ciclo é representado pelo Grupo Canindé (Devoniano Superior-Carbonífero Inferior), incluindo as formações Itaim, Pimenteira, Cabeças, Longá e Poti (Góes et al., 1992). Essas formações representam depósitos continentais que registram várias incursões marinhas. O terceiro ciclo (Carbonífero Superior- 
Permiano Inferior) é formado pelo Grupo Balsas, sendo constituído das formações Piauí e Pedra de Fogo (Góes et al., 1992), depositadas em mar raso passando para lago (lago mare, Della Fávera, 2001) e ambientes desérticos, além de basaltos e diabásios (formações Mosquito e Sardinha) que afloram na porção central da bacia.

\section{MATERIAL E MÉTODOS}

Foram coletadas 18 amostras de arenitos finos e muito finos em 13 perfis litoestratigráficos para análise de minerais pesados (Figura 1B). Destas, quatro foram laminadas e estudadas com microscópio petrográfico para caracterização textural e composicional. Os minerais pesados foram separados da fração 0,125-0,062 mm com bromofórmio e montados em lâminas de vidro. Foram avaliados de modo semiquantitativo, por contagem de, no mínimo, 100 grãos, excluindo micas, com microscópio petrográfico ZEISS, modelo AXIOLAB. A análise textural (texturas superficiais e internas) de minerais foi realizada com microscópio eletrônico de varredura (MEV), marca LEO 1450, do Museu Paraense Emílio Goeldi e da Universidade Federal do Pará. Inicialmente, os grãos foram selecionados sob lupa binocular, montados em suportes de alumínio ou fita dupla-face e metalizados com ouro. Utilizou-se o modo de emissão de elétrons secundários para observar texturas superficiais e o de elétrons retroespalhados para estudar feições internas e diferenças de composição dos grãos secionados e polidos. Análises químicas semiquantitativas de grãos de turmalina, zircão e granada foram realizadas por espectrometria de raios-X por energia dispersiva (EDS), utilizando-se detector Gresham acoplado ao MEV. Todas as análises ocorreram com voltagem de $20 \mathrm{kV}$ e tempo de contagem de 30 segundos. De turmalina, foram analisados $\mathrm{Si}, \mathrm{Ti}, \mathrm{Al}, \mathrm{Fe}(\mathrm{tot})$, $\mathrm{Mn}, \mathrm{Mg}, \mathrm{Ca}, \mathrm{Na}$ e K, cujos resultados foram tratados no programa TOURMAL (Yavuz, 1997) e interpretados nos diagramas ternário Al-Fe(tot)-Mg e binário $\mathrm{Ca} /(\mathrm{Ca}+\mathrm{Na}$ ) vs $\mathrm{Fe} /(\mathrm{Fe}+\mathrm{Mg})$ (Henry \& Guidotti, 1985). De zircão, foram analisados $\mathrm{Zr}, \mathrm{Hf}, \mathrm{Y}, \mathrm{Nb}$ e, de granada, os elementos $\mathrm{Si}$, $\mathrm{Fe}(\mathrm{tot}), \mathrm{Mn}, \mathrm{Ca}, \mathrm{Mg}, \mathrm{Cr}, \mathrm{Ti}, \mathrm{Al}$, sendo os resultados tratados no programa MINPET.

\section{RESULTADOS}

\section{PETROGRAFIA}

Os arenitos, na maioria das vezes carbonáticos, formam camadas lateralmente contínuas ou lenticulares. Podem ocorrer intercalados com argilitos, no sudeste da área de estudo, ou com carbonatos, no noroeste da área. Segundo a classificação de Pettijohn et al. (1987), os arenitos são quartzo-arenitos, com cimento dolomítico, textura fina a média, grãos subarredondados e bem selecionados (Figura 3). São constituídos de quartzo e, subordinadamente, de plagioclásio e microclínio. $\bigcirc$ quartzo é monocristalino e exibe comumente sobrecrescimento sintaxial. Os grãos apresentam contatos pontuais, raramente retilíneos, e são cimentados com dolomita espática. Além de preencher espaços intersticiais, o cimento dolomítico também substituiu, parcialmente, grãos do arcabouço.

\section{MINERAIS PESADOS}

\section{Caracterização e distribuição por associação de fácies}

Os minerais pesados, oriundos de diferentes fácies arenosas, demonstram grande similaridade mineralógica, mas ocorrem variações percentuais significativas entre as amostras estudadas. A assembléia é dominada por zircão, granada, turmalina, barita, rutilo e estaurolita, ocorrendo, esporadicamente, cianita, hornblenda, anatásio, espinélio, monazita, sillimanita e andaluzita (Figura 4 e Tabela 1). Esses minerais apresentam ampla variedade de formas e texturas superficiais.

Os grãos de zircão, com frequência de 4 a 70\%, apresentam, em geral, formas prismáticas, frequentemente com terminações bipiramidais, com arestas mais ou menos desgastadas, variando de 

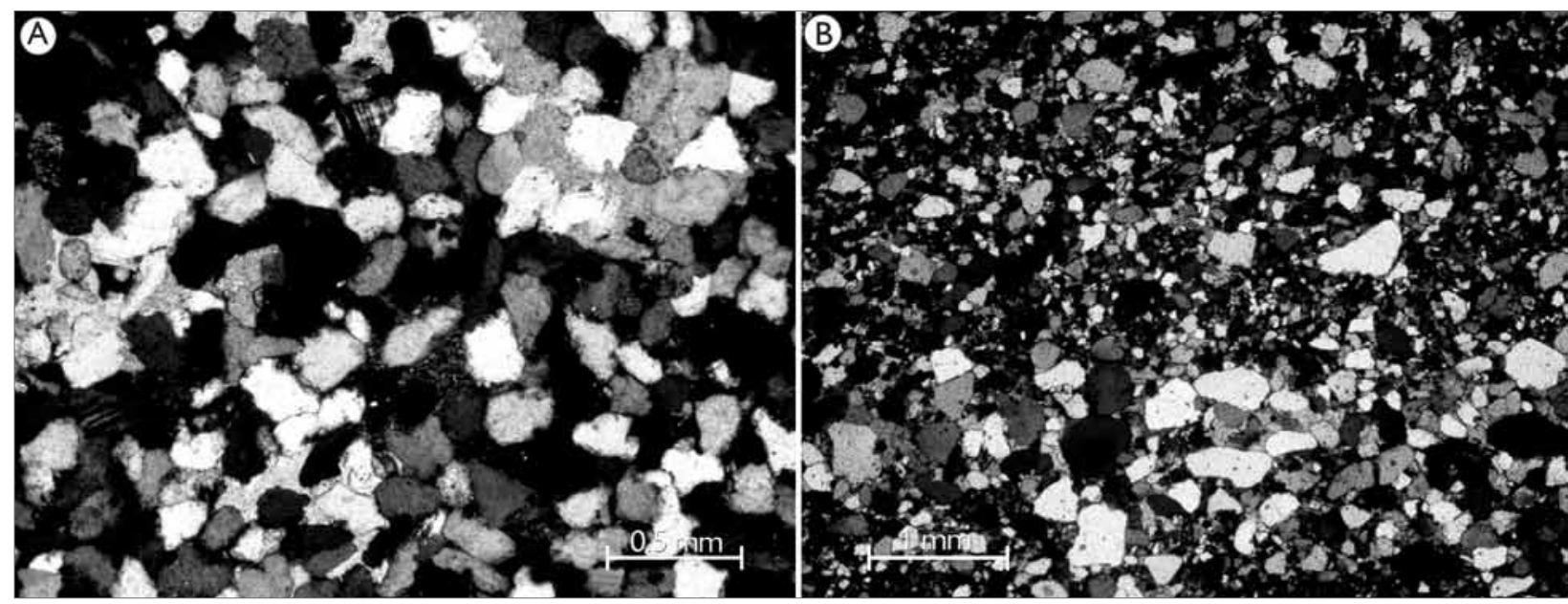

Figura 3. Fotomicrografias de quartzo-arenito com cimento dolomítico (A e B). Polarizadores cruzados.

incolores a levemente rosados (Figura 4). A presença de zoneamento nessas formas é comum. Ocorrem, ainda, grãos equidimensionais arredondados a subangulosos, incolores, rosados e levemente castanhos, em parte com inclusões de minerais opacos. São observadas na superfície dos grãos marcas de impacto e fraturas conchoidais (Figura 5D) e, internamente, zoneamento concêntrico (Figura 5E). Com menos frequência, foram registrados grãos metamíticos. Os grãos de zircão dominam nas frentes deltaicas $(\approx 50 \%)$, sendo menos abundantes na barra distal e no prodelta/plataforma $(\approx$ 15\%). Os grãos de granada, com frequência entre $12 \mathrm{e}$ $74 \%$, são incolores a levemente acastanhados, exibindo, geralmente, formas equidimensionais com grau de arredondamento subanguloso a subarredondado (Figura 4). Com menos frequência, ocorrem grãos prismáticos alongados. Como texturas superficiais, encontram-se, frequentemente, facetas de corrosão (etch-facets) bem formadas, enquanto fraturas conchoidais são mais raras (Figura 5A). Internamente, os grãos de granada são homogêneos ou apresentam algumas inclusões de quartzo. A granada é mais abundante na barra distal $(\approx 40 \%)$ e, em menor quantidade, na frente deltaica $(\approx 24 \%)$. Nos ambientes de frente deltaica com retrabalhamento por ondas e prodelta/plataforma os teores são de $\approx 30 \%$. Os grãos de turmalina variam de 3 a 20\% do total de pesados e mostram, geralmente, formas prismáticas ou irregulares (Figuras 4 e 5B). As formas prismáticas são estreitas, de cores esverdeada e marrom escura. Nos grãos irregulares, que são mais abundantes, predominam cores marrom esverdeada e raramente azul. Fraturas conchoidais e marcas de impacto são pouco frequentes, ao contrário das feições de dissolução, observadas em superfície e internamente (Figura 5C). Os teores de turmalina são baixos nas frentes deltaicas e no prodelta/plataforma $(\approx 9 \%$ ), apenas na barra distal são um pouco mais elevados $(\approx 13 \%)$. A barita é abundante em seis amostras, variando de 18 a 55\%, enquanto nas demais não ultrapassa 3\%. O mineral exibe formas irregulares arredondadas a angulosas e superfície bastante corroída, geralmente em forma de cavidades rômbicas (Figuras 4 e 5G). Os teores mais elevados de barita ocorrem na barra distal, chegando até 55\%, e no prodelta/ plataforma, com teor máximo de 50\%. Nas outras associações, os teores são muito baixos $(\approx 2 \%)$. 0 rutilo, com teores de 1 a $8 \%$, tem formas prismáticas subédricas, mas ocorrem também grãos irregulares subarredondados e subangulosos (Figura 4). Suas cores são vermelha e amarela escura. Os teores de rutilo são

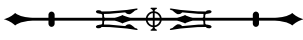




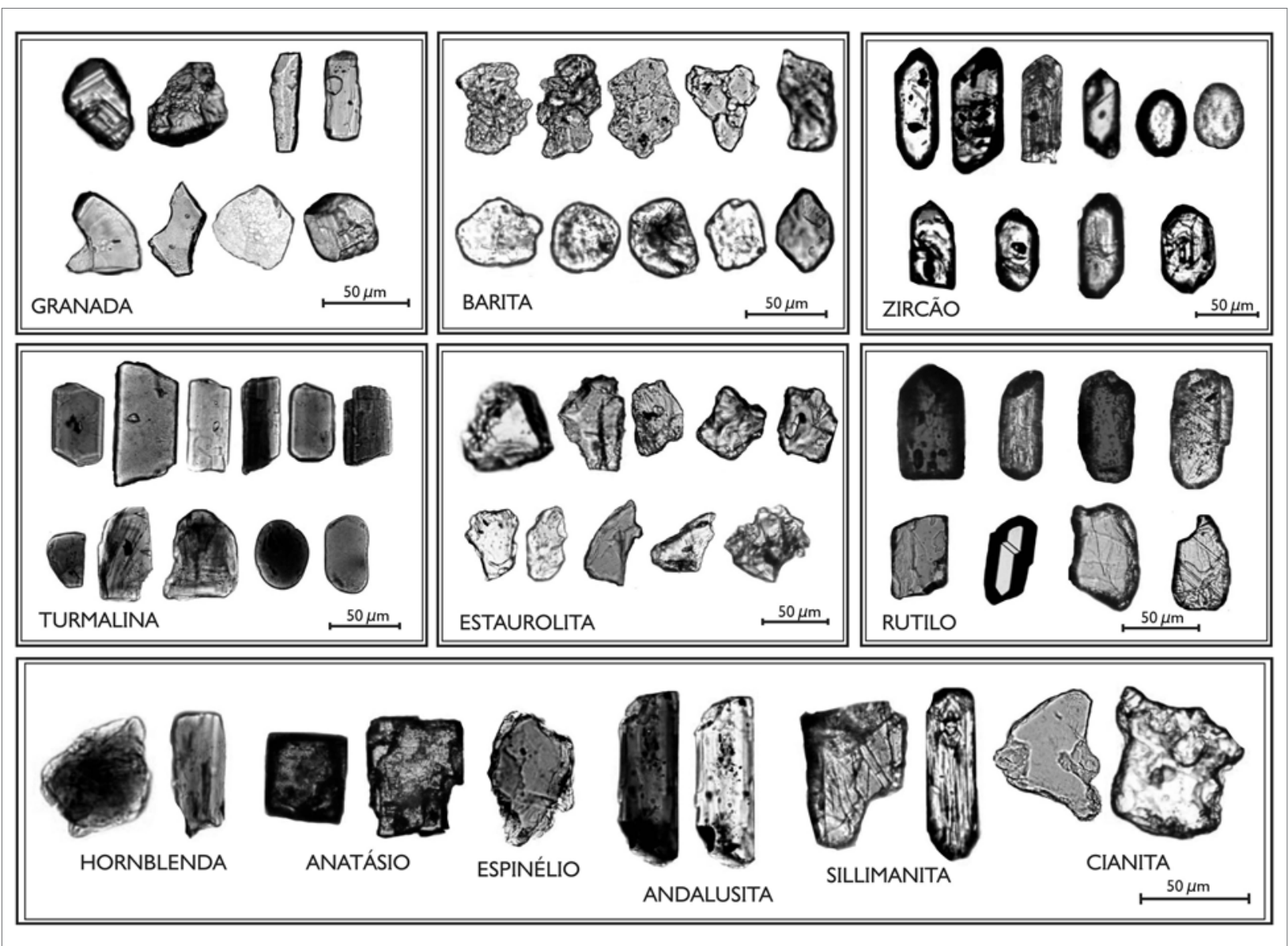

Figura 4. Fotomicrografias de minerais pesados de arenitos albianos, borda leste da bacia de São Luís-Grajaú. Polarizadores paralelos.

relativamente constantes nas quatro associações $(\approx$ 5\%). Os grãos de estaurolita, variando de 1 a 9\%, são irregulares angulosos e apresentam diversos tons de amarelo e avermelhado (Figura 4). Fraturas conchoidais são frequentes, além de feições de dissolução, que incluem marcas mamilares, 'cristas de galo' e cavidades lenticulares orientadas (Figura 5F). Na frente deltaica, o teor de estaurolita $(\approx 6 \%)$ é duas vezes maior que nos outros ambientes $(\approx 3 \%)$. Os demais minerais ocorrem mais esporadicamente e incluem cianita, exibindo, geralmente, grãos irregulares, em parte com inclusões de minerais opacos (Figura 4); hornblenda, que apresenta grãos irregulares subarredondados, esverdeados, pouco corroídos, e grãos prismáticos esverdeados, com arestas desgastadas (Figura 4); anatásio autigênico idiomórfico, acastanhado a marrom (Figura 4); espinélio, cujos grãos irregulares são verdes e têm poucas inclusões e fraturas (Figura 4); monazita, apresentando grãos arredondados, com cor amarela clara; sillimanita, com grãos prismáticos alongados (Figura 4); e andaluzita, com formas prismáticas alongadas e muitas inclusões e fraturas (Figura 4).

\section{Variações composicionais de turmalina}

Os minerais do grupo da turmalina têm elevada estabilidade e composição química relativamente complexa. Embora haja um grande número de composições de membros finais, a maioria das variações pode ser descrita em termos

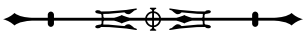




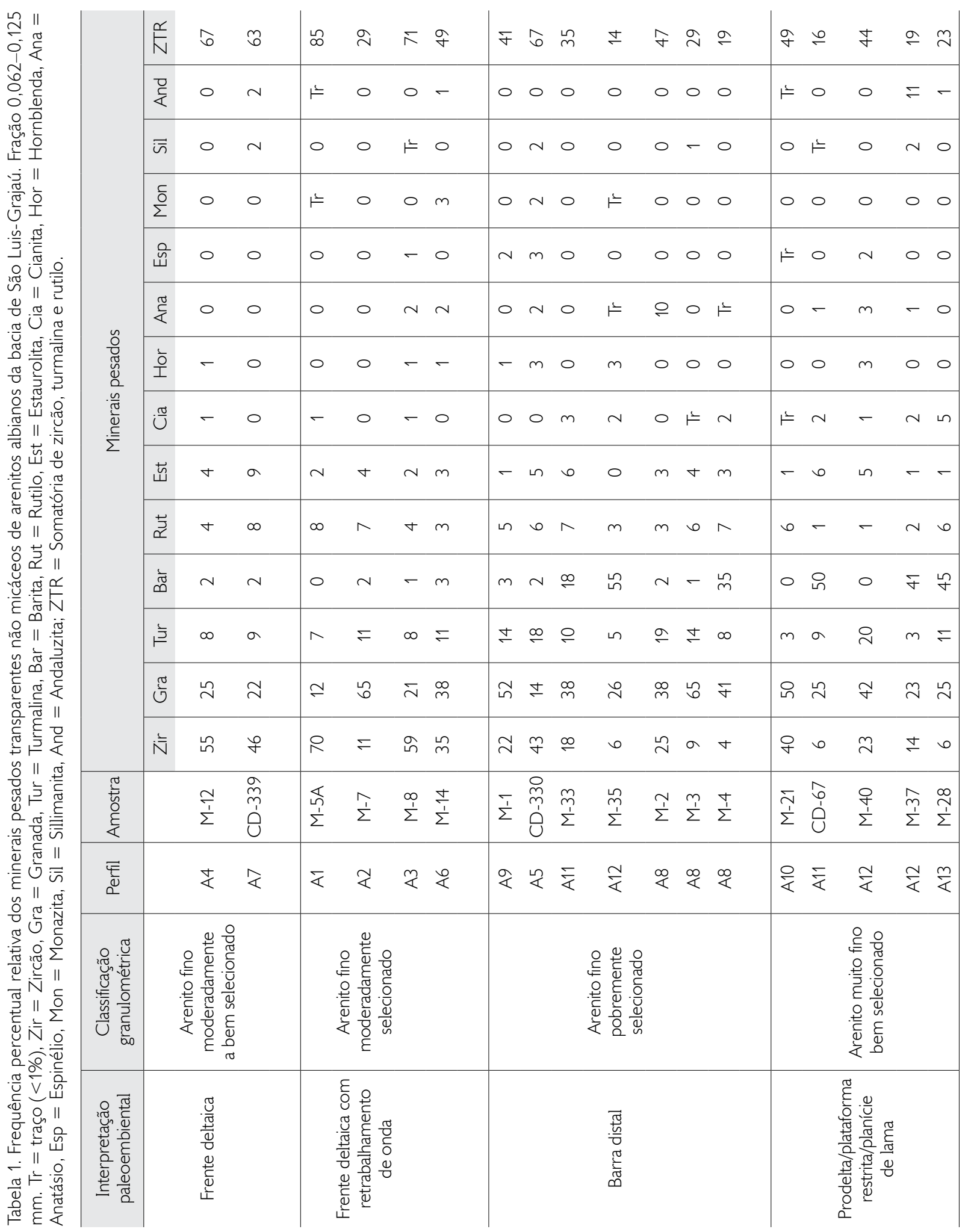



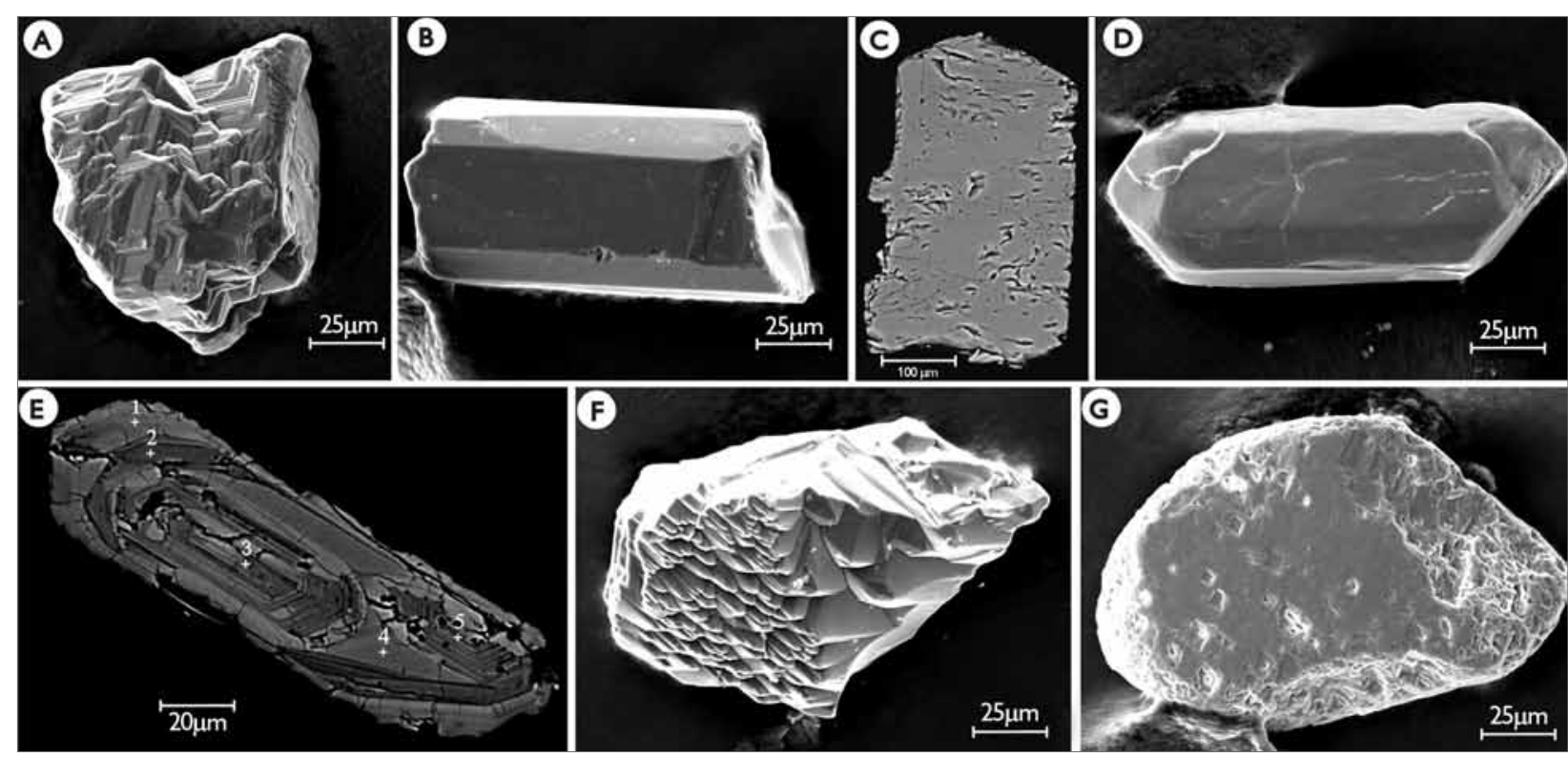

Figura 5. Imagens de microscópio eletrônico de varredura (MEV) de granada (A), turmalina (B e C), zircão (D e E), estaurolita (F) e barita (G). C e E: imagens de elétrons retro-espalhados, as demais: imagens de elétrons secundários.

da abundância de Fe e Mg. Os tipos de turmalina mais comuns são shorlita, dravita, uvita e elbaita. Dravita e uvita indicam fonte tipicamente metamórfica ou metassomática, enquanto shorlita e elbaita têm paragêneses graníticas ou pegmatíticas (Morton, 1991). A composição química de turmalinas tem demonstrado grande aplicabilidade em estudos de proveniência, utilizando-se, por exemplo, teores de Fe, Al, Mg e Ca (Henry \& Guidotti, 1985) ou de Ti e Zn (Viator, 2003).

Neste trabalho, foram analisados 87 grãos de turmalina de oito amostras, totalizando 139 análises pontuais (Tabela 2). O diagrama binário $\mathrm{Ca} /(\mathrm{Ca}+\mathrm{Na})$ vs $\mathrm{Fe} /(\mathrm{Fe}+\mathrm{Mg})$ define a presença de dravita com $87 \%$ do total dos grãos estudados, enquanto shorlita perfaz 13\% (Figura 6A). No diagrama triangular $\mathrm{Al}-\mathrm{Al}_{50} \mathrm{Fe}(\text { tot })_{50}{ }^{-}$ $\mathrm{Al}_{50} \mathrm{Mg}_{50}$, são discriminados principalmente dois campos litológicos (Figura 6B): campo 4, indicando metapelitos e metapsamitos aluminosos; e campo 5, caracterizando metapelitos e metapsamitos pobres em alumínio. Rochas granitóides do campo 1 são subordinadas como fonte (Henry \& Guidotti, 1985).

\section{Variações composicionais de zircão}

Zircão é um mineral de elevada resistência aos processos de erosão, intemperismo, transporte e diagênese (Morton, 1985a; Hallsworth et al., 2000). Ocorre como mineral acessório em grande variedade de rochas ígneas ácidas e intermediárias, sendo raro em rochas máficas e ultramáficas (Heaman \& Tarney, 1989). É encontrado também em metamorfitos, em parte como grãos arredondados (Poldervaart, 1950). Por ser de alta resistência, é frequente em rochas sedimentares. Considerando os fatores que influenciam a cristalização do zircão, como temperatura, pressão, fugacidade de oxigênio e composição inicial do magma, pode-se admitir que este mineral herde a assinatura geoquímica característica de sua fonte (Belousova \& Griffin, 2002).

Análises químicas de cristais de zircão, provenientes de diferentes tipos de rocha ígnea, demonstraram variações expressivas no conteúdo de alguns elementos traços presentes na sua estrutura, com destaque para $\mathrm{Hf}, \mathrm{Y}, \mathrm{Nb}$, Ce, Ta, ETR, P, U e Th (Murali et al., 1983; Pupin, 2000). Tais variações permitem utilizar a composição do zircão

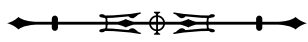


Tabela 2. Análises de espectrometria de raios-X por energia dispersiva (EDS) de turmalinas de arenitos albianos da borda leste da bacia de São Luís-Grajaú.

\begin{tabular}{|c|c|c|c|c|c|c|c|c|}
\hline Amostra & $M-2$ & $M-5 A$ & $M-33$ & $M-7$ & $M-3$ & $M-12$ & M-8 & M-14 \\
\hline \multicolumn{9}{|c|}{ Peso em \% (média) } \\
\hline $\mathrm{B}_{2} \mathrm{O}_{3}^{*}$ & 10,63 & 10,62 & 10,67 & 10,67 & 10,70 & 10,66 & 10,69 & 10,86 \\
\hline $\mathrm{SiO}_{2}$ & 38,58 & 38,92 & 38,83 & 39,11 & 38,86 & 38,16 & 39,06 & 40,30 \\
\hline $\mathrm{TiO}_{2}$ & 0,75 & 0,51 & 0,72 & 0,61 & 0,64 & 0,58 & 0,58 & 0,55 \\
\hline $\mathrm{Al}_{2} \mathrm{O}_{3}$ & 34,29 & 33,93 & 34,04 & 33,66 & 34,32 & 35,35 & 33,79 & 33,65 \\
\hline $\mathrm{FeO} * *$ & 6,33 & 6,10 & 6,49 & 5,78 & 5,71 & 6,30 & 5,98 & 5,31 \\
\hline $\mathrm{MnO}$ & 0,11 & 0,15 & 0,15 & 0,14 & 0,20 & 0,19 & 0,14 & 0,11 \\
\hline $\mathrm{MgO}$ & 6,30 & 7,03 & 6,28 & 7,07 & 6,56 & 5,99 & 6,85 & 6,11 \\
\hline $\mathrm{CaO}$ & 0,85 & 0,58 & 0,74 & 0,68 & 0,64 & 0,69 & 0,61 & 0,95 \\
\hline $\mathrm{Na}_{2} \mathrm{O}$ & 1,76 & 2,09 & 1,99 & 2,11 & 2,10 & 1,66 & 2,15 & 2,38 \\
\hline $\mathrm{K}_{2} \mathrm{O}$ & 0,06 & 0,06 & 0,07 & 0,06 & 0,06 & 0,77 & 0,05 & 0,05 \\
\hline Total & 99,66 & 99,99 & 99,98 & 99,89 & 99,79 & 100,35 & 99,9 & 100,27 \\
\hline
\end{tabular}

* $\mathrm{B}_{2} \mathrm{O}_{3}$ calculado com base em 29 oxigênios

*** Ferro total como FeO

como um indicador em potencial da natureza do magma a partir do qual ele cristalizou. Além disso, como na maioria das rochas ígneas saturadas em sílica, o zircão é o principal mineral contendo $\mathrm{Hf}$, a razão $\mathrm{Zr} / \mathrm{Hf}$ do zircão deve ser próxima da razão do magma original (Vlasov, 1966).

Foram analisados 56 grãos de zircão em oito amostras, totalizando 95 análises pontuais. Seus resultados, apresentados nos diagramas Hf-Y-Nb (Figura 7A) e Zr/Hf vs Y (Figura 7B), indicam a presença de duas populações distintas. Os grãos de zircão apresentam razões $\mathrm{Zr} / \mathrm{Hf}$ de 10 a 60, com concentrações entre 22 a 37 e média de 29. A razão $U / T h$ é $\geq 0,5$, caracterizando sua origem magmática.

\section{Variações composicionais de granada}

Granada é um mineral comum em diferentes tipos de rochas metamórficas, granitos, pegmatitos, rochas vulcânicas ácidas, kimberlitos e algumas rochas metassomáticas (Deer et al., 1982). A composição química das granadas pode ser correlacionada às condições físico-químicas sob as quais se formaram as rochas das quais se originam, embora haja sobreposição de campos composicionais de granadas com diferentes paragêneses/origens (Wright, 1938).

A identificação da área fonte é possível, embora a mistura de diferentes fontes, causada pela complexidade da área fonte original ou pela reciclagem e diagênese, possa limitar, de modo considerável, a interpretação. Apesar das dificuldades apresentadas, estudos de proveniência de arenitos usando variações composicionais de granadas detríticas têm sido realizados com sucesso (Morton, 1985b, 1991; Takeuchi, 1994; Asiedu et al., 2000).

Granadas ricas em componente almandina são típicas de xistos e gnaisses, resultantes de metamorfismo regional de rochas pelíticas. Podem ocorrer também em alguns granitos, granodioritos, riolitos e andesitos. Granadas da série almandina-espessartita são conhecidas em rochas graníticas peraluminosas (Du Bray, 1988). Granadas ricas em espessartita encontram-se em metapelitos, metasilex e xistos. Melanita, grandita rica em Ti, é típica de fonolitos. Granadas ricas em Ca (grossulária, 


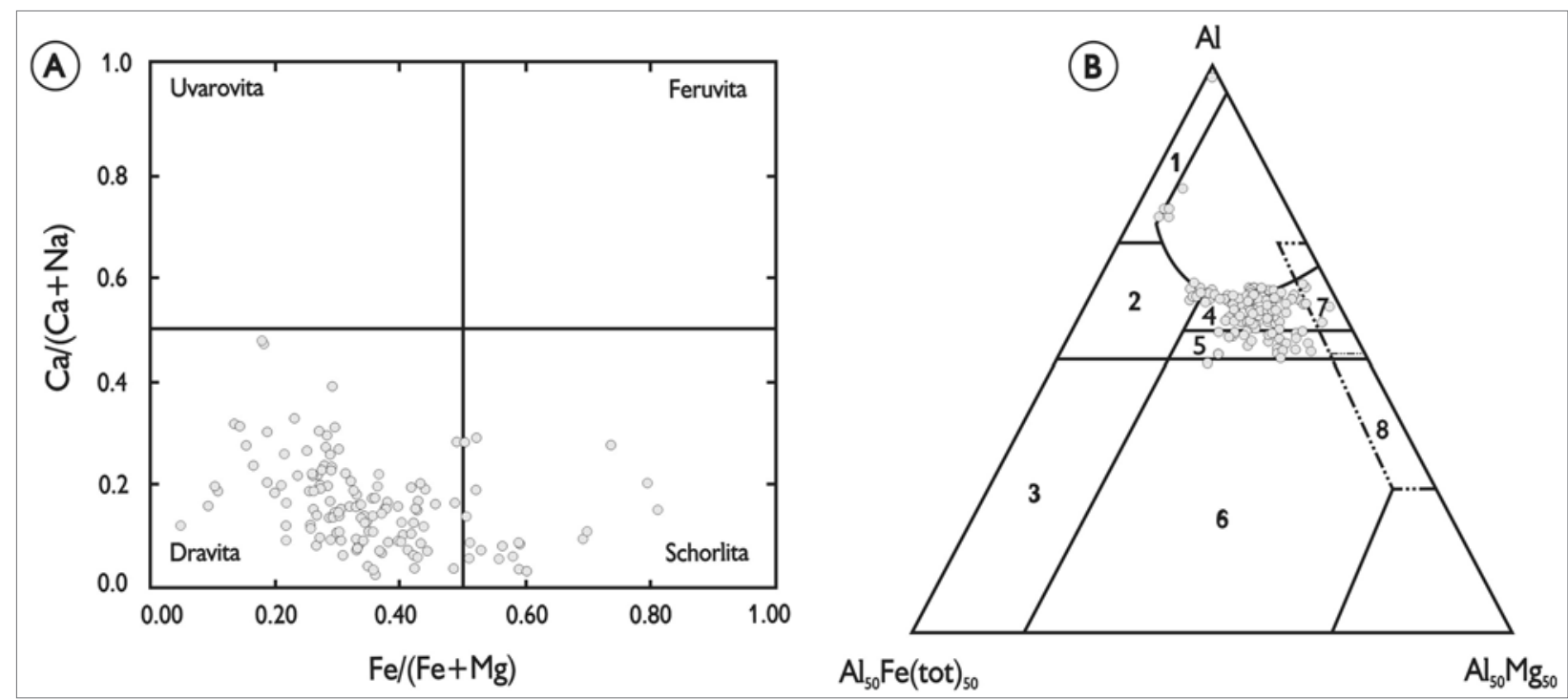

Figura 6. Composição semi-quantitativa (análises EDS) de turmalinas de arenitos albianos, apresentada em diagrama $\mathrm{Ca} /(\mathrm{Ca}+\mathrm{Na})$ vs Fe/ (Fe+Mg) (A) e diagrama Al-Fe(tot)-Mg (B) (Henry \& Guidotti, 1985): (1) granitóides, pegmatitos e aplitos ricos em Li; (2) granitóides, pegmatitos e aplitos pobres em Li; (3) rochas graníticas alteradas hidrotermalmente; (4) metapelitos e metapsamitos ricos em Al; (5) metapelitos e metapsamitos pobres em Al; (6) rochas de quartzo e turmalina ricas em Fe ${ }^{3+}$, cálcio-silicáticas e metapelitos; (7) rochas meta-ultramáficas com baixo teor de Ca; e (8) metacarbonatos e metapiroxenitos.

andradita) são restritas a rochas carbonáticas impuras de metamorfismo de contato, eskarnitos metassomáticos e xistos formados de calcários impuros por metamorfismo regional. Já serpentinitos, kimberlitos e granulitos contêm granadas ricas em piropo (Tröger, 1969; Füchtbauer, 1974; Deer et al., 1982; Meagher, 1982; Mange \& Maurer, 1992). Piropo com cromo é mineral-guia na prospecção de diamante (Suguio, 2003).

Foram analisados 46 grãos de seis amostras, totalizando 126 análises pontuais, cujos resultados estão apresentados nos diagramas triangulares espessartita + grossulária - piropo - almandina e grossulária + andradita - espessartita - piropo + almandina (Figura 8), bem como na Tabela 3. Os resultados relativos à composição química das granadas indicam, assim como os de turmalina e zircão, vários tipos de rochafonte. A composição química das granadas define pelo menos dois grupos distintos, ambos ricos em almandina, mas mostrando diferenças nos teores de espessartita, grossulária e andradita (Figura 8).

\section{DISCUSSÃO E CONCLUSÕES}

Identificações com microscópio óptico e análises químicas semiquantitativas de minerais pesados provenientes de arenitos albianos na borda leste da bacia de São LuísGrajaú, aliadas aos dados petrográficos destes arenitos, permitem caracterizar seus principais tipos de rocha-fonte e variações em composição do mesmo tipo.

Os arenitos albianos consistem, principalmente, em quartzo e, subordinadamente, em plagioclásio e microclínio. São quartzo-arenitos com cimento carbonático, que sugerem proveniência de blocos continentais compostos principalmente de rochas ígneas e metamórficas e de orógenos 'reciclados' (Dickinson, 1985).

Regiões denominadas de blocos continentais são regiões consolidadas tectonicamente, formadas de cinturões orogênicos antigos amalgamados, enquanto que orógenos 'reciclados', caracterizando cinturões dobrados, incluem estratos supracrustais deformados e soerguidos, formados dominantemente por rochas metassedimentares (Dickinson, 1985). Os sedimentos 


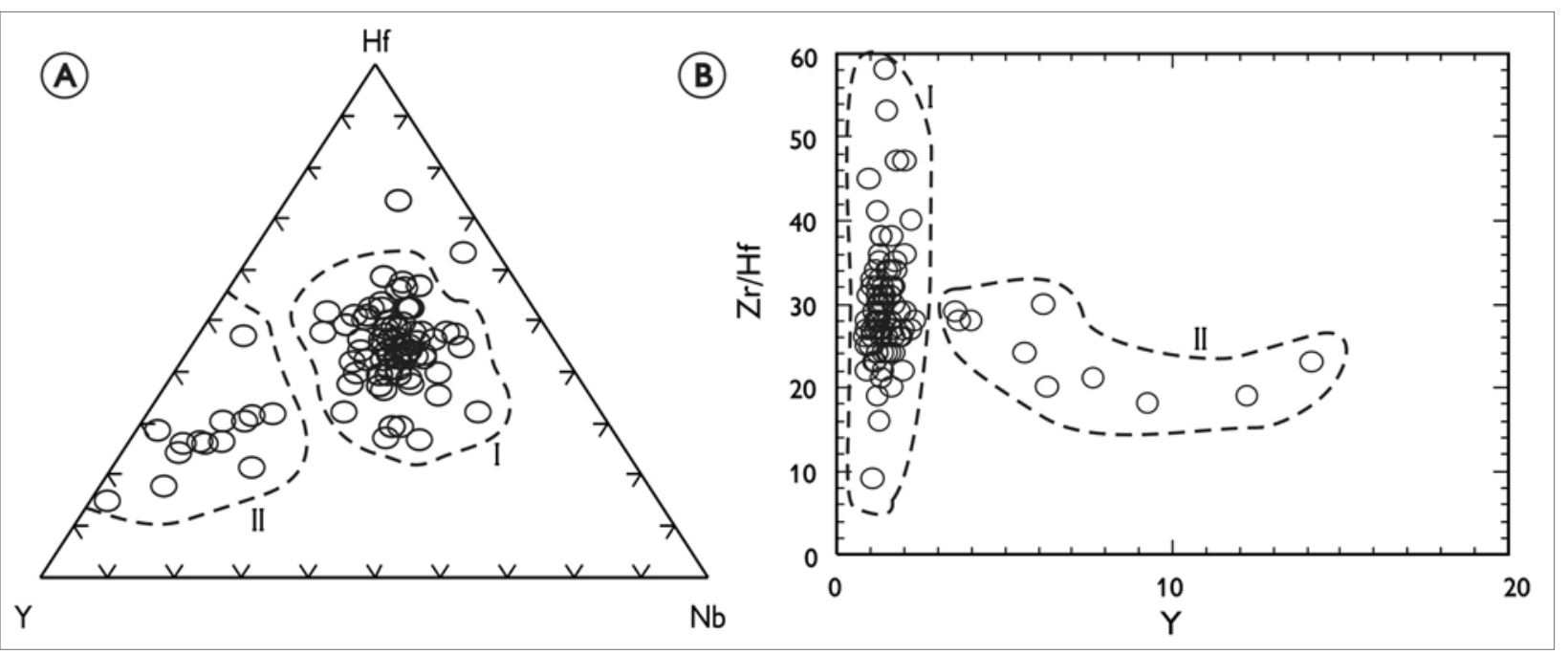

Figura 7. Composição semi-quantitativa (análises EDS) de zircões de arenitos albianos, apresentada em diagrama Hf-Y-Nb (\% peso) (A) e diagrama Zr/Hf vs Y (\% peso) (B).

derivados de regiões como estas normalmente apresentam alta maturidade textural e composicional, com baixas concentrações de feldspato (Dickinson, 1985), à semelhança dos arenitos albianos aqui estudados e daqueles da borda sul da bacia de São Luís-Grajaú (Nascimento \& Góes, 2006).

Os depósitos albianos ocorrem próximo da borda leste atual da bacia, onde foram acumulados diretamente sobre o embasamento paleozóico e pré-cambriano, que também contorna a bacia. Com base na progradação do sistema deltaico para ENE/E e ESE, mostrada por Miranda \& Rossetti (2006), sugere-se que as áreas mais prováveis do embasamento como fontes potenciais de depósitos albianos sejam a bacia do Parnaíba, as faixas Araguaia e Gurupi, bem como o cráton São Luís.

Os minerais pesados, principalmente zircão, granada, turmalina, barita, estaurolita e rutilo, sugerem proveniências mistas, com histórias distintas, para os arenitos albianos. A ocorrência de grãos arredondados e subarredondados de minerais ultraestáveis (zircão, turmalina e rutilo) e suas texturas superficiais apontam seu caráter multicíclico, o que é consistente com a maturidade composicional dos arenitos estudados. Já os grãos euédricos e subédricos de turmalina e zircão sugerem origem primária a partir de rochas ígneas/ metamórficas. Segundo Krynine (1946), é questionável admitir a mesma proveniência para grãos euédricos e arredondados presentes em uma mesma amostra.

Na distribuição por associação de fácies, o zircão apresenta valores relativamente elevados nas frentes deltaicas, possivelmente em função da maior dinâmica deposicional nesses ambientes. Já na barra distal e no ambiente de prodelta/plataforma restrita, a energia deposicional mais baixa poderia ter sido responsável por uma concentração menor deste mineral. Entretanto, o aumento nítido de barita nestes últimos ambientes, bem como a tendência das proporções crescentes de rutilo/ zircão em direção ao topo dos perfis sugerem mudança(s) de área-fonte. Rutilo e zircão têm comportamento similar durante os processos de transporte, deposição e diagênese. Portanto, variações nos valores da razão rutilo/ zircão podem apontar mudanças de proveniência durante a deposição (Morton \& Hallsworth, 1994).

Ozircão, cuja forma original é controlada pela velocidade de cristalização, composição do magma e temperatura, mostra variações na composição química e forma, ocorrendo, além de grãos arredondados, grãos euédricos com zoneamento 


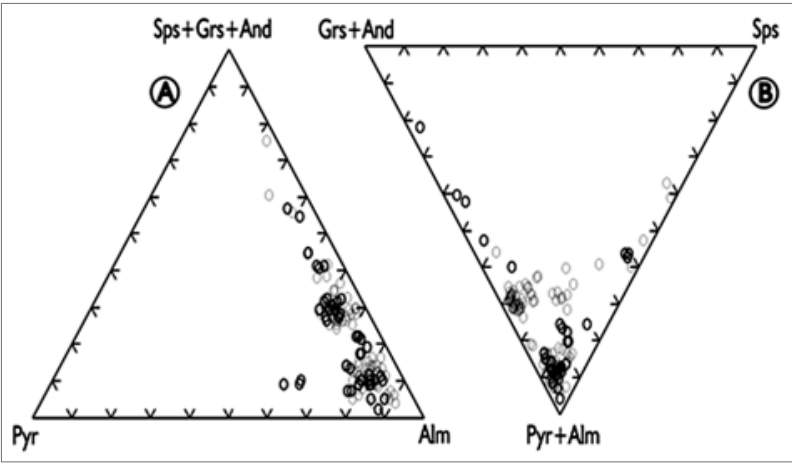

Figura 8. Composição semi-quantitativa (análises EDS) de granadas de arenitos albianos, apresentada em diagrama ternário. Pyr= Piropo; Alm= Almandina; Sps= Espessartita; Grs= Grossulária; And $=$ Andradita.

concêntrico, que indicam contribuição de fontes ígneas (Corfu et al., 2003). Grãos sem zonação interna, considerados como sendo totalmente recristalizados, sugerem proveniência de fontes metamórficas (Corfu et al., 2003). Todavia, a textura homogênea pode ser apenas aparente, já que não pode ser totalmente revelada pela técnica empregada.

A maioria dos grãos de zircão analisados mostrou razão $U / T h \geq 0,5$, confirmando sua proveniência de fontes ígneas (Pidgeon et al., 2000; Corfu et al., 2003; Hoskin \& Schaltegger, 2003; Cavosie et al., 2004). Valores da razão $\mathrm{Zr} / \mathrm{Hf}$, variando principalmente de 22 a 37 , com média de 29 , indicam como fontes rochas graníticas e, provavelmente, migmatitos (Pupin, 2000). Como indicam os diagramas $\mathrm{Hf}-\mathrm{Y}-\mathrm{Nb}$ e $\mathrm{Zr} / \mathrm{Hf}$ vs $\mathrm{Y}$ (Figuras 7A e B), existiram pelo menos duas fontes ígneas diferentes para o zircão.

A composição química de turmalinas aponta diferentes tipos de rochas-fonte para os depósitos estudados. Predominam turmalinas magnesianas (dravita) e ricas em ferro (shorlita), diagnósticas de fontes, tais como metapelitos, metapsamitos e granitóides. O diagrama Al$\mathrm{Fe}(\mathrm{tot})-\mathrm{Mg}$ sugere metapelitos e metapsamitos aluminosos (campo 4) e pobres em Al (campo 5) como as principais fontes de turmalina dos arenitos albianos (Figura 6; Henry \& Guidotti, 1985). Já rochas granitóides, pegmatitos e aplitos são menos representativas como fontes.
Assim como turmalina e zircão, também os grãos de granada provieram de várias fontes. Sua composição, exibida nos diagramas da Figura 8, define pelo menos duas fontes para esse mineral. As análises químicas demonstram que as granadas são ricas em almandina e apresentam conteúdo variável em espessartita, grossulária e piropo. Granadas geralmente são de origem metamórfica, o que deve valer também para as de arenitos albianos. Quando são de origem magmática, estes minerais ocorrem em granitos peraluminosos (Du Bray, 1988). Granada é relativamente estável sob condições alcalinas, mas pouco estável em fluidos com pH $<7$ (Morton, 1984; 1985b). Em áreas áridas ou semiáridas, as bases fortes de $\mathrm{Na}, \mathrm{K}$, Ca e Mg são retidas, tornando o ambiente intempérico alcalino. Sob estas condições, elevados teores de granada em arenitos albianos foram preservados. Esta interpretação paleoclimática é também compatível com a presença de argilominerais irregulares illita/esmectita, de origem detrítica, em pelitos albianos da área de estudo. Estes minerais se formam em áreas com moderada a baixa precipitação, pobre drenagem e água de solo neutra a alcalina (Chamley, 1989; Rossetti et al., 2001b).

Barita tem ocorrência restrita na porção noroeste da área estudada. Em geral, este mineral pode ser encontrado como cimento em arenitos, produto autigênico em carbonatos e em veios hidrotermais acompanhando sulfetos (Tröger, 1969; Füchtbauer, 1988; Milliken \& Mack, 1990). A origem da barita nos depósitos albianos é desconhecida e espera por um estudo mais detalhado.

Rutilo é mineral típico de rochas metamórficas (xistos, gnaisses e anfibolitos), sendo raramente encontrado em rochas ígneas e pegmatitos. Estaurolita é um incontestável mineral indicativo de eventos metamórficos de médio a alto grau, estando presente em micaxistos, granada-xistos e, raramente, em paragnaisses pobres em feldspato. Outros minerais que indicam ainda fontes de origem metamórfica e ocorrem com teores muito baixos e esporadicamente nos arenitos albianos incluem cianita, andaluzita e sillimanita. Cianita é a fase de $\mathrm{Al}_{2} \mathrm{SiO}_{5}$ estável a pressões altas, 
Tabela 3. Análises de espectrometria de raios-X por energia dispersiva (EDS) de granadas de arenitos albianos da borda leste da bacia de São Luís-Grajaú.

\begin{tabular}{|c|c|c|c|c|c|c|}
\hline Amostra & $M-5 A$ & M-33 & M-8 & M-14 & M-12 & M-3 \\
\hline \multicolumn{7}{|c|}{ Peso em \% (média) } \\
\hline $\mathrm{SiO}_{2}$ & 36,5 & 36,36 & 36,76 & 36,53 & 36,12 & 36,33 \\
\hline $\mathrm{Al}_{2} \mathrm{O}_{3}$ & 20,83 & 20,75 & 20,61 & 21,11 & 20,87 & 20,94 \\
\hline $\mathrm{TiO}_{2}$ & 0,3 & 0,2 & 0,49 & 0,16 & 0,16 & 0,18 \\
\hline $\mathrm{Cr}_{2} \mathrm{O}_{3}$ & 0,2 & 0,13 & 0,22 & 0,12 & 0,16 & 0,14 \\
\hline $\mathrm{MgO}$ & 1,67 & 1,25 & 1,39 & 1,63 & 2,39 & 1,44 \\
\hline $\mathrm{CaO}$ & 2,24 & 4,41 & 8,85 & 6,67 & 2,37 & 6,09 \\
\hline $\mathrm{MnO}$ & 3,46 & 5,25 & 0,81 & 2,36 & 4,38 & 1,52 \\
\hline $\mathrm{FeO} *$ & 35,14 & 31,59 & 31,1 & 31,43 & 33,51 & 33,31 \\
\hline Total & 100,34 & 99,94 & 100,23 & 100,01 & 99,96 & 99,95 \\
\hline \multicolumn{7}{|c|}{ Número de cátions } \\
\hline Si & 2,96 & 2,96 & 2,96 & 2,95 & 2,94 & 2,95 \\
\hline $\mathrm{Al}$ & 0,04 & 0,04 & 0,04 & 0,05 & 0,06 & 0,05 \\
\hline $\mathrm{Al}$ & 1,96 & 1,95 & 1,91 & 1,96 & 1,94 & 1,95 \\
\hline $\mathrm{Ti}$ & 0,02 & 0,01 & 0,03 & 0,01 & 0,01 & 0,01 \\
\hline $\mathrm{Fe}^{+3}$ & 0,02 & 0,05 & 0,08 & 0,06 & 0,08 & 0,07 \\
\hline $\mathrm{Cr}$ & 0,01 & 0,01 & 0,01 & 0,01 & 0,01 & 0,01 \\
\hline $\mathrm{Mg}$ & 0,20 & 0,15 & 0,17 & 0,20 & 0,29 & 0,17 \\
\hline $\mathrm{Ca}$ & 0,19 & 0,38 & 0,76 & 0,58 & 0,21 & 0,53 \\
\hline$M n$ & 0,24 & 0,36 & 0,05 & 0,16 & 0,30 & 0,10 \\
\hline $\mathrm{Fe}^{+2}$ & 2,36 & 2,10 & 2,01 & 2,06 & 2,20 & 2,19 \\
\hline Piropo & 6,74 & 5,06 & 5,56 & 6,54 & 9,67 & 5,81 \\
\hline Espessartina & 7,94 & 12,1 & 1,84 & 5,38 & 10,1 & 3,48 \\
\hline Almandina & 78,8 & 70 & 67,2 & 68,8 & 73,4 & 73,1 \\
\hline Grossulária & 4,74 & 9,87 & 20,9 & 16 & 2,37 & 13,8 \\
\hline Andradita & 1,12 & 2,54 & 3,8 & 2,83 & 4 & 3,37 \\
\hline Uvarovita & 0,64 & 0,42 & 0,7 & 0,38 & 0,51 & 0,45 \\
\hline
\end{tabular}

* Ferro total como FeO

enquanto andaluzita e sillimanita são formadas a pressões relativamente mais baixas, andaluzita a temperaturas mais baixas e sillimanita a temperaturas mais elevadas (Tröger, 1969). Cianita ocorre em gnaisses, granulitos e em xistos gerados durante metamorfismo regional de rochas pelíticas, estando acompanhada frequentemente por rutilo, estaurolita, almandina, hornblenda ou mica (Tröger, 1969; Mange \& Maurer, 1992). Andaluzita é um mineral típico de metamorfismo de contato, embora ocorra também no campo de metamorfismo regional e raramente em rochas 
graníticas. Sillimanita, como mineral de metamorfismo regional, é encontrado em gnaisses, granulitos e micaxistos. Anatásio é de origem autigênica e formado durante os processos diagenéticos nos arenitos. A formação deste mineral está relacionada com a disponibilidade de titânio, provavelmente proveniente de ilmenita, já que esse mineral apresenta frequentes feições de dissolução química, ficando, assim, evidente que grande parte da ilmenita não resistiu aos processos pós-deposicionais e forneceu titânio para formação de anatásio.

Os dados obtidos na análise dos minerais pesados neste trabalho, aliados aos da evolução do sistema deltaico da área de estudo (Miranda \& Rossetti, 2006), não permitem estabelecer uma relação direta acerca da proveniência dos arenitos albianos. Mas é possível afirmar, com base no método clássico de análise de minerais pesados e nas análises químicas de zircão, turmalina e granada, que as fontes desses arenitos foram vários tipos de rochas metamórficas e ígneas, relacionadas, provavelmente, aos cinturões neoproterozóicos Araguaia e Gurupi, ao cráton São Luís, bem como a rochas sedimentares da bacia do Parnaíba. O simples registro da presença de minerais nas áreas-fonte, sem sua especificação química, é ambíguo. Zircão, turmalina, estaurolita, cianita e granada, por exemplo, ocorrem tanto na faixa Araguaia como no cinturão Gurupi (Hasui et al., 1984a; Hasui et al., 1984b; Moura et al., 2003). A composição química de zircão, turmalina e granada contribui para detalhar a assinatura química de rochas-fonte de arenitos albianos na bacia de São Luís-Grajaú e é a base para estudos futuros mais detalhados sobre a proveniência destes depósitos.

\section{AGRADECIMENTOS}

Os autores agradecem à Universidade Federal do Pará (UFPA) e ao Museu Paraense Emílio Goeldi (MPEG) pela infra-estrutura fornecida, à Profa. Ana Maria Góes (USP) pelas sugestões e discussões, aos Profs. Hilton Costi (MPEG) e Cláudio Lamarão (UFPA) pela ajuda com as análises de microscopia eletrônica de varredura, bem como aos revisores pelas críticas e correções que enriqueceram a versão final do trabalho.

\section{REFERÊNCIAS}

ANAISSE JR., J., W. TRUCKENBRODT \& D. F. ROSSETTI, 2001. Fácies de um sistema estuarino-lagunar no Grupo Itapecuru, região de Açailândia/MA, Bacia do Grajaú. In: D. F. ROSSETTI, A. M. GÓES \& W. TRUCKENBRODT (Eds.): O Cretáceo na Bacia de São Luís-Grajaú: 119-150. Museu Paraense Emílio Goeldi (Coleção Friedrich Katzer), Belém.

ANANI, C. Y., 1999. Sandstone petrology and provenance of the Neoproterozoic Voltaian Group in the southeastern Voltaian Basin, Ghana. Sedimentary Geology 128: 83-98.

ASIEDU, D. K., S. SUZUKI \& T. SHIBATA, 2000. Provenance of sandstones from the lower Cretaceous Sasayama Group, Inner Zone of Southwest Japan. Sedimentary Geology 131: 9-24.

BELOUSOVA, E. A. \& W. L. GRIFFIN, 2002. Igneous zircon: trace element composition as an indicator of source rock type. Contributions to Mineralogy and Petrology 143: 602-622.

BRITO NEVES, B. B., E. J. SANTOS \& W. R. VAN SCHMUS, 2001. Tectonic history of the Borborema Province, northeastern Brazil. In: U. G. CORDANI, E. J. MILANI, A. THOMAZ FILHO \& D. A. CAMPOS (Eds.): Tectonic evolution of South América. Proceedings of the Thirty-first Iternational Geological Congress 31: 151-182.

CAPUTO, M. V. \& E. C. LIMA, 1984. Estratigrafia, idade e correlaçãa do Grupo Serra Grande - Bacia do Parnaíba. Anais do $33^{\circ}$ Congresso Brasileiro de Geologia 2: 740-759

CAVOSIE, A. J., S. A. WILDEB, D. LIUC, P. W. WEIBLEND \& J. W. VALLEYA, 2004. Internal zoning and U-Th-Pb chemistry of Jack Hills detrital zircons: a mineral record of early Archean to Mesoproterozoic (4348-1576 Ma) magmatism. Precambrian Research 135: 251-279.

CHAMLEY, H., 1989. Clay sedimentology: 1-623. Springer, Berlin.

CORDANI, U. G., B. B. BRITO NEVES, R. A. FUCK, R. PORTO, F. A. THOMAZ \& F. M. CUNHA, 1984. Estudo preliminar da integração do Pré-Cambriano com eventos tectônicos das bacias sedimentares brasileiras: 15: 1-70. PETROBRÁS (Série Ciência-Técnica-Petróleo, Seção Exploração de Petróleo), Rio de Janeiro.

CORFU, F., J. M. HANCHAR, P.W. O. HOSKIN \& P. KINNY, 2003. Atlas of zircon textures. In: J. M. HANCHAR \& P. W. O. HOSKIN (Eds.): Zircon. Reviews in mineralogy \& geochemistry. Mineralogical Society of America Geochemical Society 53: 469-500.

DEER, W. A., R. A. HOWIE \& J. ZUSSMAN, 1982. Rock-Forming minerals: Orthosilicates: 467-649. Longmar, Londres. 
DELLA FÁVERA, J. C., 2001. Fundamentos de Estratigrafia Moderna: 1-263. Ed. Universidade do Estado do Rio de Janeiro, Rio de Janeiro.

DICKINSON, W. R., 1985. Interpreting provenance relations from detrital modes of sandstones. In: G. G. ZUFFA (Ed.): Provenance of Arenites: 333-361. Reidel, Dordrecht.

DU BRAY, E. A., 1988. Garnet compositions and their use as indicators of peraluminous granitoid petrogenesis - southeastern Arabian Shield. Contributions to Mineralogy and Petrology 100: 205-212.

FÜCHTBAUER, H. (Ed.), 1974. Sediments and sedimentary rocks 1: 1-464. Schweizerbart'sche Verlagsbuchhandlung, Stuttgart.

FÜCHTBAUER, H. (Ed.), 1988. Sedimente und Sedimentgesteine: 1-1141. Schweizerbart'sche Verlagsbuchhandlung, Stuttgart.

GÓES, A. M. O., W. A. TRAVASSOS \& K. C. NUNES, 1992. Projeto Parnaíba - Reavaliação da bacia e perspectivas exploratórias. PETROBRÁS (relatório interno), Belém.

GÓES, A. M. \& D. F. ROSSETTI, 2001. Gênese da Bacia de São LuísGrajaú, Meio-Norte do Brasil. In: D. F. ROSSETTI, A. M. GÓES \& W. TRUCKENBRODT (Eds.): O Cretáceo na Bacia de São Luís-Grajaú: 15-30. Museu Paraense Emílio Goeldi (Coleção Friedrich Katzer), Belém.

HALLSWORTH, C. R., A. C. MORTON, J. C. CLAOUÉ-LONG \& C. M. FANNING, 2000. Carboniferous sand provenance in the Pennine Basin, UK: constraints from heavy mineral and SHRIMP zircon age data. Sedimentary Geology 137: 147-185.

HASUI, Y., J. B. S. COSTA \& F. A. M. ABREU, 1984a. Província Tocantins Setor setentrional. In: F. F. M. ALMEIDA \& Y. HASUI (Eds.): O Pré-Cambriano do Brasil: 187-204. Ed. Blücher, São Paulo.

HASUI, Y., F. A. M. ABREU \& R. N. N. VILLAS, 1984b. Província Parnaíba. In: F. F. M. ALMEIDA \& Y. HASUI (Eds.): O Pré-Cambriano do Brasil: 36-45. Ed. Blücher, São Paulo.

HEAMAN, L. M. \& J. TARNEY, 1989. U-Pb baddeleyite ages for the Scourie dyke swarm, Scotland: evidence for two distinct intrusion events. Nature 340: 705-708.

HENRY, D. J. \& C. V. GUIDOTTI, 1985. Tourmaline as a petrogenetic indicator mineral: an example from the staurolite-grade metapelites of NW Maine. American Mineralogist 70: 1-15.

HOSKIN, P. W. O. \& U. SCHALTEGGER, 2003. The composition of zircon and igneous and metamorphic petrogenesis. In: J. M. HANCHAR \& P. W. O. HOSKIN (Eds.): Zircon. Reviews in mineralogy \& geochemistry. Mineralogical Society of America Geochemical Society 53: 27-62.

KLEIN, E. L., C. A. V. MOURA \& B. L. S. PINHEIRO, 2005. Paleoproterozoic crustal evolution of the São Luís Craton, Brazil: evidence from zircon geochronology and $\mathrm{Sm}-\mathrm{Nd}$ isotopes. Gondwana Research 8: 177-186.
KRYNINE, P. D., 1946. The tourmaline group in sediments. Journal of Geology 54: 65-87.

LIMA, R. D. \& D. F. ROSSETTI, 2001. Análise faciológica e seqüencial de depósitos de delta de baía (Neocretáceo), Bacia do Grajaú, MA. In: D. F. ROSSETTI, A. M. GÓES \& W. TRUCKENBRODT (Eds.): O Cretáceo na Bacia de São Luís-Grajaú: 151-175. Museu Paraense Emílio Goeldi (Coleção Friedrich Katzer), Belém.

MANGE, M. A. \& H. F. W. MAURER, 1992. Heavy mineral in colour: 1-147. Chapman \& Hall, London.

MEAGHER, E. P., 1982. Silicates garnets. In: P. H. RIBEE (Ed.): Orthosilicates. Reviews in mineralogy \& geochemistry. Mineralogical Society of America Geochemical Society 5: 25-66.

MILLIKEN, K. L. \& L. E. MACK, 1990. Subsurface dissolutions of heavy minerals, Frio Formation sandstones of the ancestral Rio Grande Province, South Texas. Sedimentary Geology 68: 187-199.

MIRANDA, M. C. C. \& D. F. ROSSETTI, 2006. Reconstituição paleoambiental de depósitos albianos na borda leste da bacia de Grajaú, MA. Revista Brasileira de Geociências 36: 623-635.

MORTON, A. C., 1984. Stability of detrital heavy minerals in Tertiary sandstones from the North Sea Basin. Clay Minerals 19: 287-308.

MORTON, A. C., 1985a. Heavy minerals in provenance studies. In: G. G. ZUFFA (Ed.): Provenance of Arenites: 249-277. Reidel, Dordrecht.

MORTON, A. C., 1985b. A new approach to provenance studies: electron microprobe analysis of detrital garnets from Middle Jurassic sandstones of the northern North Sea. Sedimentology 32: 553-566.

MORTON, A. C., 1991. Geochemical studies of detrital heavy minerals and their application to provenance research. In: A. C. MORTON, S. P. TODD \& P. D. W. HAUGHTON (Eds.): Developments in Sedimentary Provenance Studies: 31-45. Geological Society, London.

MORTON, A. C. \& C. HALLSWORTH, 1994. Identifying provenience-specific features of detrital heavy mineral assemblages in sandstones. Sedimentary Geology 90: 241-256.

MORTON, A. C. \& C. HALLSWORTH, 1999. Processes controlling the composition of heavy mineral assemblages in sandstones. Sedimentary Geology 124: 3-29.

MOURA, C. A. V., F. A. M. ABREU, E. L. KLEIN, E. S. M. PALHETA \& B. L. S. PINHEIRO, 2003. Geochronology of the São Luís Craton and the Gurupi Belt, Brazil. South American Symposium on Isotope Geology 4: 225-228.

MURALI, A. V., R. PARTHASARATHY, T. M. MAHADEVAN \& M. SANKAR, 1983. Trace element characteristics, REE patterns and partition coefficients of zircons from different geological environments - a case study on Indian zircons. Geochimica Cosmochimica Acta 47: 2047-2052.

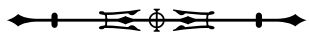


NASCIMENTO, M. S. \&A. M. GÓES, 2006. Petrografia de arenitos e texturas de minerais pesados e quartzo: uma contribuição ao estudo da proveniência de depósitos albianos na borda sul da Bacia de São Luís-Grajaú. In: Boletim do Simpósio sobre o Cretáceo do Brasil. UNESP, São Paulo.

OWEN, M. R., 1987. Hafnium content of detrital zircons: A new tool for provenance study. Journal of Sedimentary Petrology 57: 824-830.

PAZ, J. D. S. \& D. F. ROSSETTI, 2001. Reconstrução paleoambiental da Formação Codó (Aptiano), borda leste da Bacia do Grajaú, MA. In: D. F. ROSSETTI, A. M. GÓES \& W. TRUCKENBRODT (Eds.): O Cretáceo na Bacia de São Luís-Grajaú: 77-100. Museu Paraense Emílio Goeldi (Coleção Friedrich Katzer), Belém.

PETTIJOHN, F. J., P. E. POTTER \& R. SIEVER (Eds.), 1987. Sand and sandstones: 1-553. Springer-Verlag, Berlin.

PIDGEON, R. T., M. J. B. MACAMBIRA \& J. M. LAFON, 2000. Th-U-Pb isotopic systems and internal structures of complex zircons from an enderbites from the Pium Complex, Carajás Province, Brazil: evidence for the ages of granulite facies metamorphism and protolith of the enderbite. Chemical Geology 166: 159-171.

POLDERVAART, A., 1950. Statistical studies of zircon as a criterion in granitization. Nature 165: 574-575.

PUPIN, J. P., 2000. Granite genesis related to geodynamics from $\mathrm{Hf}-\mathrm{Y}$ in zircon. Transactions of the Royal Society of Edinburgh Earth Science 91: 245-256.

ROSSETTI, D. F., 2001. Arquitetura deposicional da Bacia de São Luís-Grajaú, Meio-Norte do Brasil. In: D. F. ROSSETTI, A. M. GÓES \& W. TRUCKENBRODT (Eds.): O Cretáceo na Bacia de São Luís-Grajaú: 31-46. Museu Paraense Emílio Goeldi (Coleção Friedrich Katzer), Belém.

ROSSETTI, D. F. \& W. TRUCKENBRODT, 1997. Revisão estratigráfica para os depósitos do Albiano-Terciário Inferior (?) na Bacia de São Luís, Maranhão. Boletim do Museu Paraense Emílio Goeldi, série Ciências da Terra 9: 29-41.

ROSSETTI, D. F., A. M. GÓES \& M. ARAI, 2001a. A passagem Aptiano-Albiano na Bacia do Grajaú, Maranhão. In: D. F. ROSSETTI, A. M. GÓES \& W. TRUCKENBRODT (Eds.): O Cretáceo na Bacia de São Luís-Grajaú: 101-117. Museu Paraense Emílio Goeldi (Coleção Friedrich Katzer), Belém.
ROSSETTI, D. F., W. TRUCKENBRODT \& A. E. A. SANTOS JR., 2001b. Clima do Cretáceo no Meio-Norte brasileiro. In: D. F. ROSSETTI, A. M. GÓES \& W. TRUCKENBRODT (Eds.): O Cretáceo na Bacia de São Luís-Grajaú: 67-76. Museu Paraense Emílio Goeldi (Coleção Friedrich Katzer), Belém.

SANTOS, E. J. \& B. B. BRITO NEVES, 1984. Província Borborema. In: F. F. M. ALMEIDA \& Y. HASUI (Eds.): O Pré-Cambriano do Brasil: 123-186. Ed. Blücher, São Paulo.

SANTOS JÚNIOR, A. E. A. \& D. F. ROSSETTI, 2003. Paleoambiente e estratigrafia da Formação Ipixuna, área do Rio Capim, leste da SubBacia de Cametá. Revista Brasileira de Geociências 33(3): 313-324.

SUGUIO, K., 2003. Geologia Sedimentar:1-400. Ed. Blücher, São Paulo.

TAKEUCHI, M., 1994. Changes in garnet chemistry show a progressive denudation of the source areas for Permian-Jurassic sandstones, southern Kitakami Terrane, Japan. Sedimentary Geology 93: 85-105.

TRÖGER, W. E., 1969. Optische Bestimmung der gesteinsbildenden Minerale. Teil 2 Textband: 1-822. Schweizerbart'sche Verlagsbuchhandlung, Stuttgart.

VIATOR, D. B., 2003. Detrital tourmaline as an indicator of provenance: a chemical and sedimentological study of modern sands from the Black Hills, South Dakota: 1-85. Master's degree dissertation, Department of geology and geophysics, Louisiana State University, Louisiana. Disponível em: <http://etd02.ln×390. lsu.edu/docs/available/etd-0611103 -101847>. Acesso em: 12 setembro 2005

VLASOV, K. A. (Ed.), 1966. Geochemistry and Mineralogy of Rare Elements and Genetic Types of Their Deposits. I. Geochemistry of Rare Elements. Israel Program Scientific Translations, Jerusalem, Israel.

WRIGHT, W. I., 1938. The composition and occurrence of garnets. American Mineralogist 23: 436-499.

YAVUZ, F., 1997. Tourmal: software package for tourmaline, tourmaline-rich rocks and related ore deposits. Computers \& Geosciences 23: 947-959.

Recebido: 09/08/2007 Aprovado: 20/04/2009 